\title{
A Study on Natural Gas Dispersion Modeling for Gas Safety Platform Development
}

\author{
Ugwiyeon Lee and Jeong Seok Oh \\ Institute of Gas Safety R\&D, Korea Gas Safety Corporation, 1390, Wonjung-ro, \\ Maengdong-myeon, Emseong-gun, Chungcheongbuk-do, Korea \\ lyullee@gmail.com,jsoh90@gmail.com
}

\begin{abstract}
When an accident involving a gas leak happens, soon the leaked gas begins to disperse at high speed into the air. The gas cloud may have a diameter of a few kilometers according to the leakage conditions such as gas type, ambient conditions, and leakage velocity. Especially, Gas clouds made of combustible gases have wide ranges of damage by fire or gas explosion. Natural gas belonging to combustible gases also may have very wide ranges of damage because the ethane gas, as a main element of natural gas, is lighter and faster than other gases. For this reason, the calculation of the natural gas dispersion is essential for the development of Gas Safety Platform. Korea Gas Safety Corporation is developing a gas safety platform which is able to predict gas accident risks by a risk assessment system. The most important factor of the risk decision is to predict damage ranges from fire and explosion scenario. And the fire and explosion damage calculation begins from gas dispersion modeling.

This paper introduces methods for ethane gas dispersion modeling with Gaussian dispersion equations. Also, various numerical methods are recommended for efficiently calculating Gaussian equations.
\end{abstract}

\section{Keywords: Natural Gas Dispersion, Gas Safety Platform}

\section{Introduction}

Gas safety platform is a system to decide a risk in environment using natural gas, and alarms the risk for the gas users. The gas safety platform is developing based a consequence analysis system. The consequence analysis system predicts the effects of gas accidents and decides the consequence area of the gas accident risk such as fire, explosion, or toxic gas leakage. To calculate the consequence area requires modeling the gas dispersion and calculating the dispersion distance of the leaked gas.

There are many models for gas dispersion. In this study, Gaussian equations are used for lighter gases than the air. The main elements of natural gas are ethane and methane molecular which are lighter than the air. The Gaussian equations for dispersion gas modeling are divided into two types: Gaussian plume and Gaussian puff. The two types have developed for continuous releasing gas modeling and instantaneous releasing gas modeling, respectively. [2] Between plume and puff models, it is most different thing that Gaussian puff receives the time as input value. So, the Gaussian puff graph is able to be expressed dynamically [1].

It is not easy to solve the Gaussian equations by hand. So, numerical methods are required to solve the problems and draw the gas dispersion graph. In some point, the Gaussian equation is a quadratic function for finding some points corresponded to target gas concentration. This study has considered four kinds of numerical method for solving

Received (August 16, 2017), Review Result (November 23, 2017), Accepted (November 29, 2017) 
quadratic function: Bisection Method, Newton Method, Secant Method, and FalsePosition Method, and suggests the best method for Gaussian equations [1].

This paper firstly introduces the methods of gas dispersion modeling and Gaussian equations. Also, numerical methods are suggested for solving the Gaussian equations. Finally, the paper shows a various results of ethane gas dispersion modeling.

\section{Dispersion Model for Ethane Gas (Natural Gas)}

Gas dispersion model is a part of accident consequence analysis. But, gas dispersion model plays the most important role in the consequence analysis. Consequence analysis is basically composed of a three-stage system: discharge model, dispersion model, and harm potential model[1]. Again, the harm potential model is separated into 3 sub-models: Toxic model, Radiation model, and Explosion. But, the natural gas is not toxic. So, the toxic model will not be used for natural gas.

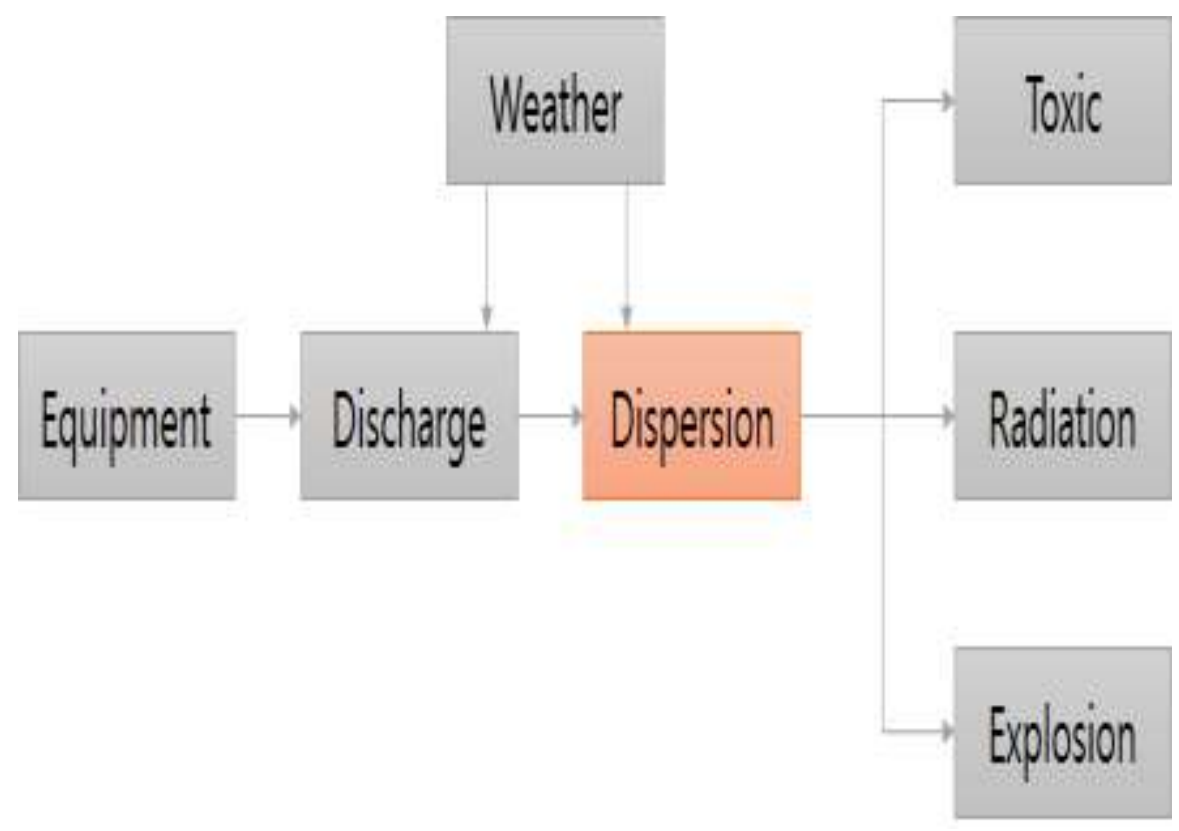

Figure 1. Consequence Analysis Process

Gas dispersion is easily influenced by many factors such as wind velocity, leakage time, and atmospheric stability. Additionally, instantaneous leakage, continuous leakage, leak velocity and leak rate are also main factors to have a strong influence on gas dispersion modeling result. The values regarding gas leakage could be derived from discharge models. Gas dispersion models generally present a result in average concentration for a time. But, real gases may be dispersed in unequal concentration that is different from the modeling results. For this reason, gas dispersion modeling is required to be very conservative in its modeling $[1,2]$.

\subsection{Atmospheric Stability and Wind Velocity}

Atmospheric stability and wind velocity are directly related to consequence area and gas concentration in the area. Atmospheric stability generally could be classified by sunshine and wind strength into six classes as A to F called Pasquill Stability Class. Letter "A" represents that the atmospheric is very unstable. On the contrary, Letter "B" refers to very stable atmosphere. Unstable atmosphere tends to reduce the dispersion distance of leaked gas. But, the more atmospheres go to a stable, the more the dispersion distance is extended. Because of these, experts have 
chosen stability class "F" for a conservative approach on gas leakage and dispersion simulations. The table of Pasquill stability class is summarized as follows (as Table 1) [1].

\section{Table 1. Pasquill Stability Class Table [1]}

\begin{tabular}{|c|c|c|c|c|c|c|}
\hline & \multicolumn{3}{|c|}{ Daytime Isolation } & \multicolumn{2}{c|}{ Nighttime Condition } & Anytime \\
\cline { 2 - 7 } $\begin{array}{c}\text { Surface Wind } \\
\text { Speed, m/s }\end{array}$ & Strong & Moderate & Slight & $\begin{array}{c}\text { Thin overcast } \\
\text { or }>4 / 8 \text { Low } \\
\text { Cloud }\end{array}$ & $\begin{array}{c}\geq 3 / 8 \\
\text { Cloudiness }\end{array}$ & $\begin{array}{c}\text { Heavy } \\
\text { overcast }\end{array}$ \\
\hline$<2$ & A & A-B & B & F & F & D \\
\hline $2 \sim 3$ & A-B & B & C & E & F & D \\
\cline { 2 - 7 } $3 \sim 4$ & B & B-C & C & D & D & D \\
\hline $4 \sim 6$ & C & C-D & D & D & D & D \\
\hline$>6$ & C & D & D & D & D & D \\
\hline
\end{tabular}

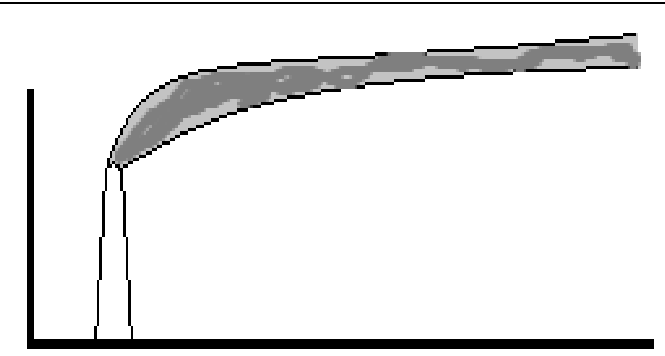

Stable (fanning), Stable Classes E, F

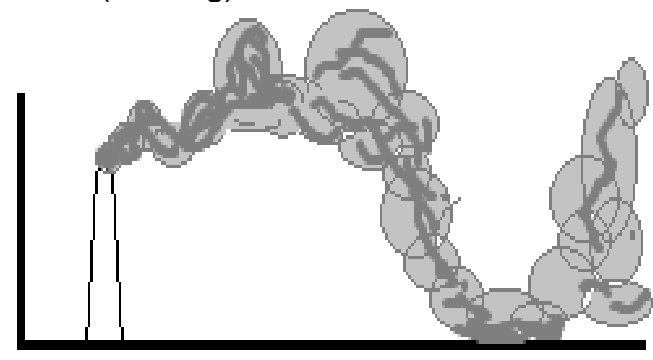

Unstable(Looping), Stability Class A,B

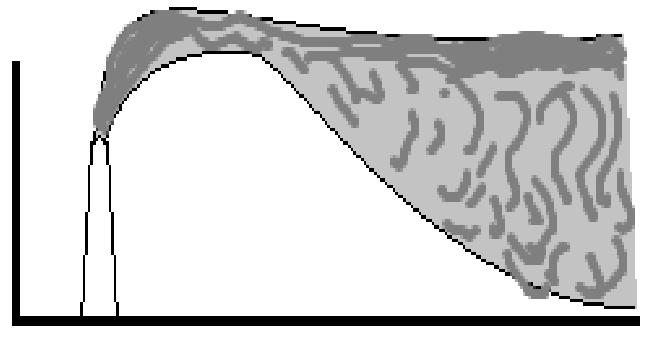

Neutral Below, Stable Above(Furnigation)

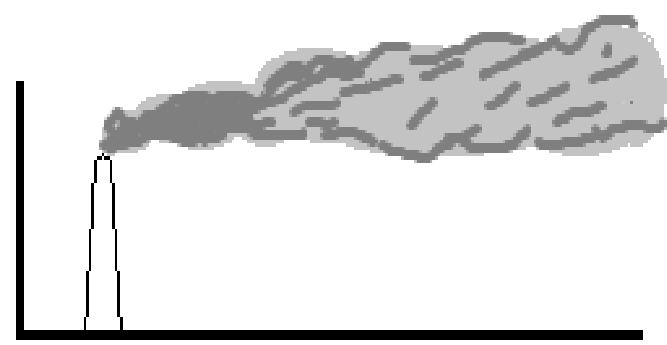

Neutral(Coning), Stability Class D

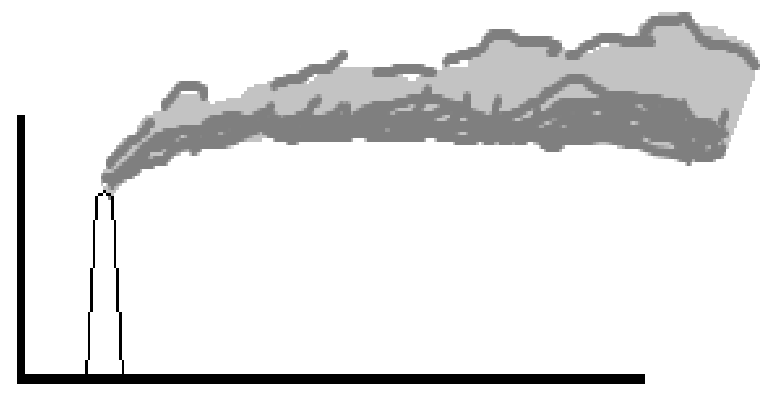

Stable Below, Neutral Aloft (Lofting)

Figure 2. Cloud Appearances by Atmospheric States [1]

Wind velocity data could be easily collected from meteorological administration. If leak point height differs from the height for measuring wind velocity, the wind velocity data need to be modified by using the following equations [2]. 


$$
u_{z}=u_{R}\left(\frac{z}{z_{R}}\right)^{p}
$$

$u_{z}$ : Wind velocity on leak point height

$u_{R}$ : Wind velocity on measured height

$z$ : Leak point height

$z_{R}$ : Measured height from a metrological administration

$p:$ Surface roughness parameter

Wind velocities are typically measured from a height of $10 \mathrm{~m}$ on the ground. This is way the $z_{R}$ value has be always set to $10 \mathrm{~m}$. Following (Table 2) represents selection criteria for surface roughness parameters about terrain classification.

Table 2. Surface Roughness Parameter, Z0, for Use with Equation [1]

\begin{tabular}{|c|l|r|}
\hline Terrain Classification & Terrain Description & $\begin{array}{l}\text { Surface roughness } \\
\text { Zn }, \text { meters }\end{array}$ \\
\hline Highly urban & $\begin{array}{l}\text { Centers of cities with tall building, very hilly or } \\
\text { mountainous area }\end{array}$ & $3-10$ \\
\hline Urban area & Centers of towns, villages, fairly level wooded country & $1-3$ \\
\hline Residential area & $\begin{array}{l}\text { Area with dense but low buildings, wooded area, } \\
\text { industrial site without large obstacle }\end{array}$ \\
\hline Large refineries & Distillation columns and other tall equipment pieces & 1 \\
\hline Small refineries & Smaller equipment, over a smaller area & 0.5 \\
\hline Cultivated land & Open area with great overgrowth, scattered houses & 0.3 \\
\hline Flat land & Few trees, long grass, fairly level grass plains & 0.1 \\
\hline Open water & Large expanses of water, desert flats & 0.001 \\
\hline Sea & Calm open sea, snow covered flat, rolling land & 0.0001 \\
\hline
\end{tabular}

For example, there was an accident involving a gas leak from a gas storage tank located in urban area. The leak point height was $1.5 \mathrm{~m}$ on the ground and wind velocity was $1.5 \mathrm{~m} / \mathrm{s}$ gotten from a metrological administration. In this case, the wind velocity on the leak point height is calculated as the follow equation.

$$
u_{z}=u_{R}\left(\frac{z}{z_{R}}\right)^{p}=1.5 m / s\left(\frac{1.5 m}{10 m}\right)^{1}=0.025 m / s
$$

\subsection{Gas Dispersion Model}

Gas dispersion model was developed from energy-mass conservation law. A gas expelled into the atmosphere begins to be mixed with air and flowed along wind velocity by turbulent diffusion force. Wind velocity typically uses $\mathrm{m} / \mathrm{s}$ unit and that could show how long the leaked gas was transferred per second. The equation (3) is an initial developed gas dispersion model that representing concentration change on a time and a position (a coordinate value) [1]. 


$$
\frac{\delta \mathrm{C}}{\delta \mathrm{t}}+\frac{\delta}{\delta \mathrm{x}_{\mathrm{i}}}\left(\mathbf{u}_{\mathrm{j}} \mathrm{C}\right)=\mathbf{0}
$$

To solve the equation (3), the gas concentration value on a time and a position is expressed as an equation of the average concentration with Eddy Diffusivity [AREA/TIME] [1].

$$
-\mathbf{K}_{\mathbf{j}} \frac{\delta \mathbf{d}}{\delta \mathbf{x}_{\mathbf{i}}}=\left\langle\mathbf{u}_{\mathbf{j}}^{\prime} \mathbf{C}\right\rangle
$$

Eddy diffusivity is calculated by a position, a time, and atmospheric condition. This value has to be decided before dispersion equation calculation. The initial gas dispersion model could be modified to the equation (5) by merging the equation (4) [1].

$$
\frac{\delta\langle\mathbf{C}\rangle}{\delta \mathrm{t}}+\left\langle\mathbf{u}_{\mathbf{j}}\right\rangle \frac{\delta\langle\mathbf{C}\rangle}{\delta \mathbf{x}_{\mathbf{i}}}=\frac{\delta \mathbf{y}}{\delta \mathbf{x}_{\mathbf{i}}}\left(\mathbf{K}_{\mathbf{j}} \frac{\delta\langle\mathbf{C}\rangle}{\delta \mathbf{x}_{\mathbf{i}}}\right)
$$

However, the equation (5) is not enough to express gas dispersion and it is not easy to calculate. So, new equations have continually been developed for a long time. Recently, gas dispersion equations tend to be separated to continuous release type and instantaneous release type. Continuous release type as called "Plume model" represents modeling of a gas continuously released from leak point. On the other hand, instantaneous release type as called "Puff model" corresponds to a released gas modeling for a short time. In this case, the gas moves in a cloud shape in the atmosphere and is spread slowly [1].

Gaussian models have the high accuracy for lighter gases than the air. Natural gas is mostly composed of Methane and Ethane which is lighter than the air. For this reason, Gaussian Equations are recommended for natural gas dispersion model. According to the release type, Gaussian model are divided into two equations: Gaussian Plume Model and Gaussian Puff Model [1].

\subsection{Continuous Release Model}

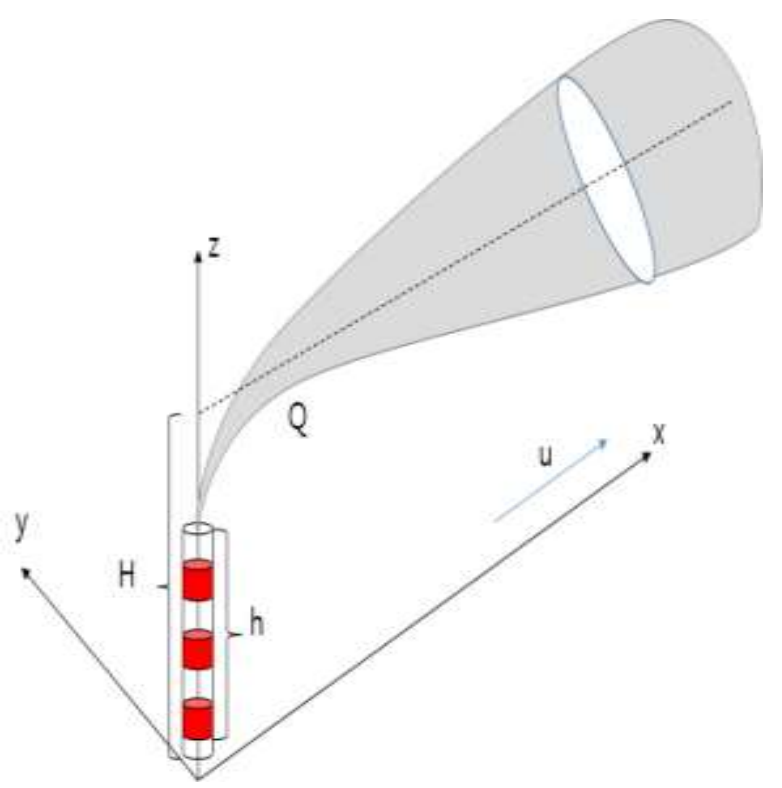

Figure 3. Continuous Released Gas Dispersion 
Gaussian Plume equation is used for gas continuous release model. The Gaussian Plume equation has a modified form from initial dispersion equation (5), and has various input values as leakage velocity, dispersion coefficients, wind velocity, and leak point height The output of Gaussian Plume equation is an average concentration value correspond to a position values ( $\mathrm{x}, \mathrm{y}, \mathrm{z}$ coordinate values) input from user. Dispersion coefficients have a form of a function using $\mathrm{x}$ coordinate values. Gaussian Plume equation and dispersion coefficient are as follows (Equation 6 \& Table 3) [1].

$\langle\mathrm{C}\rangle(\mathrm{x}, \mathrm{y}, \mathrm{z})=\frac{\mathrm{G}}{2 \pi \delta_{\mathrm{y}} \delta_{\mathrm{z}}} \exp \left[-\frac{1}{2}\left(\frac{\mathrm{y}}{\delta_{\mathrm{y}}}\right)^{2}\right] \times\left\{\exp \left[-\frac{1}{2}\left(\frac{\mathrm{z}-\mathrm{H}}{\delta_{\mathrm{z}}}\right)^{2}\right]+\exp \left[-\frac{1}{2}\left(\frac{\mathrm{z}+\mathrm{H}}{\delta_{\mathrm{z}}}\right)^{2}\right]\right\}$

$\langle\mathrm{C}\rangle$ : Average concentration (mass/volume)

$\mathrm{G}$ : Leak rate (mass/time)

$\delta_{\mathrm{y}}, \delta_{\mathrm{z}}$ : Dispersion Coefficients for $\mathrm{y}, \mathrm{z}$ coordinate (length)

$\mathrm{u}$ : Wind velocity (length/time)

y : Cross Wind Direction (length)

$\mathrm{z}$ : Distance above the ground (length)

$\mathrm{H}$ : Leak point height

Table 3. Dispersion Coefficient Equations for Gaussian Plume [1]

\begin{tabular}{|c|c|c|}
\hline Pasquill-Gifford Stability & $\boldsymbol{\delta}_{\mathbf{y}}(\mathbf{m})$ & $\boldsymbol{\delta} \mathbf{z}(\mathbf{m})$ \\
\hline Rural Condition & & \\
A & $0.22 \times(1+0.0001 \mathrm{x})^{-1 / 2}$ & $0.20 \mathrm{x}$ \\
B & $0.16 \mathrm{x}(1+0.0001 \mathrm{x})^{-1 / 2}$ & $0.12 \mathrm{x}$ \\
C & $0.11 \times(1+0.0001 \mathrm{x})^{-1 / 2}$ & $0.08 \mathrm{x}(1+0.0002 \mathrm{x})^{-1 / 2}$ \\
D & $0.08 \mathrm{x}(1+0.0001 \mathrm{x})^{-1 / 2}$ & $0.06 \mathrm{x}(1+0.0015 \mathrm{x})^{-1 / 2}$ \\
E & $0.06 \mathrm{x}(1+0.0001 \mathrm{x})^{-1 / 2}$ & $0.03 \times(1+0.0003 \mathrm{x})^{-1}$ \\
F & $0.04 \mathrm{x}(1+0.0001 \mathrm{x})^{-1 / 2}$ & $0.016 \mathrm{x}(1+0.0003 \mathrm{x})^{-1}$ \\
& & \\
\hline Urban Condition & & \\
A-B & & $0.24 \mathrm{x}(1+0.001 \mathrm{x})^{-1 / 2}$ \\
C & $0.32 \times(1+0.0004 \mathrm{x})^{-1 / 2}$ & $0.20 \mathrm{x}$ \\
D & $0.22 \mathrm{x}(1+0.0004 \mathrm{x})^{-1 / 2}$ & $0.14 \mathrm{x}(1+0.003 \mathrm{x})^{-1 / 2}$ \\
E-F & $0.16 \mathrm{x}(1+0.0004 \mathrm{x})^{-1 / 2}$ & $0.08 \mathrm{x}(1+0.0015 \mathrm{x})^{-1 / 2}$ \\
\hline
\end{tabular}

Gaussian equations need to assume the followings: Released gases do not react with the ground, and is not absorbed in the ground. There are no chemical reactions and thermodynamic effects during gas dispersion. Also, the releasing time have to be longer than the time for that the dispersing gas arrives a target point. The released gas has to be stable and it is able to stay in the air for a long time. Finally, the plume could be perfectly reflected from the ground and mixing layer, and the leak point has to be only one [1].

When a gas is releasing on the ground height, the maximum concentration point will be leak point. And the maximum concentration line matches the line $y=0$. Additionally, the Gaussian Plume equation is suitable for use in a range $\delta z<0.4 \mathrm{H}$. If 
outside in the range $\delta z<0.4 \mathrm{H}$, another equation model is required for the case. The dispersion distance (in $\delta \mathrm{z} \geq 0.4 \mathrm{H}$ ) is too far to calculate in high accuracy by Gaussian model [1].

\subsection{Instantaneous Release Model}

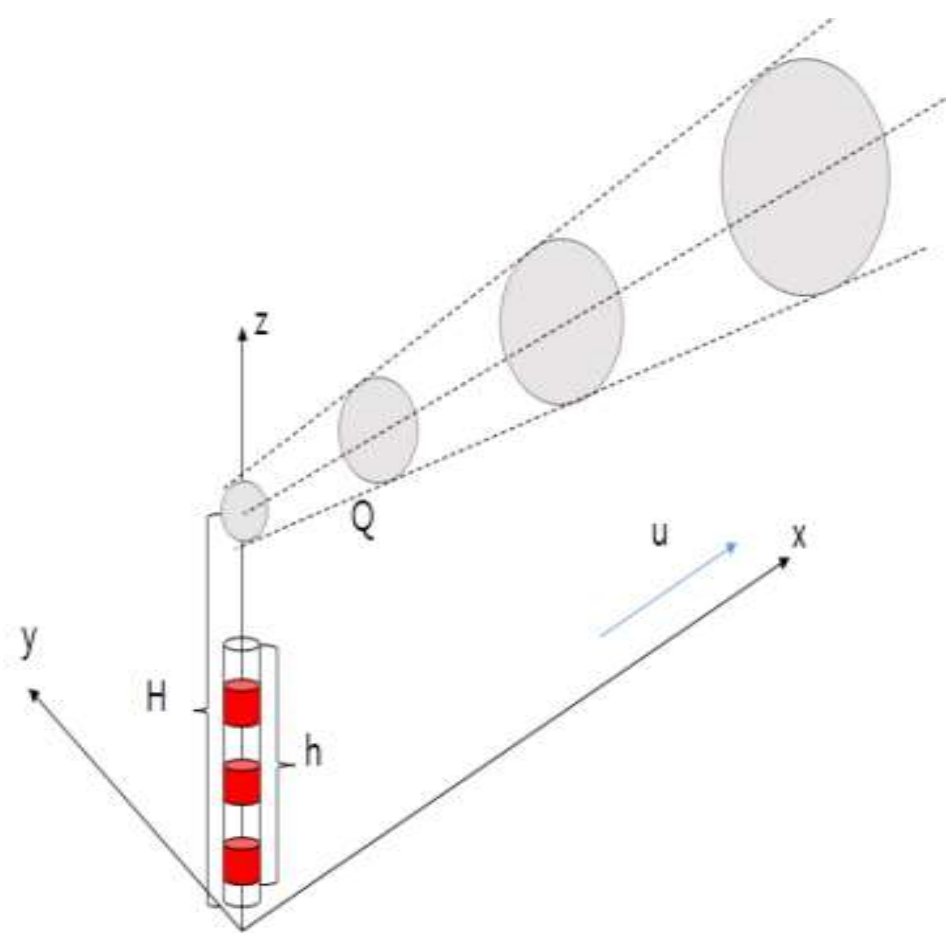

Figure 4. Instantaneous Released Gas Dispersion

Gaussian Puff equation is used for instantaneous release model. This equation requires amount of released gas, atmospheric condition, leak point height, the elapsed time, and dispersion coefficient as input valves. As Gaussian plume model, average concentration is also the output of Gaussian Puff equation. But, the dispersion coefficient function for Gaussian Puff makes no distinction between urban area and rural area unlike Gaussian Plume [1].

$\langle\mathrm{C}\rangle(\mathrm{x}, \mathrm{y}, \mathrm{z})=\frac{\mathrm{G}^{*}}{(2 \pi)^{3 / 2} \delta_{\mathrm{x}} \delta_{\mathrm{y}} \delta_{\mathrm{z}}} \exp \left[-\frac{1}{2}\left(\frac{\mathrm{y}}{\delta_{\mathrm{y}}}\right)^{2}\right] \times\left\{\exp \left[-\frac{1}{2}\left(\frac{\mathrm{z}-\mathrm{H}}{\delta_{\mathrm{z}}}\right)^{2}\right]+\exp \left[-\frac{1}{2}\left(\frac{\mathrm{z}+\mathrm{H}}{\delta_{\mathrm{z}}}\right)^{2}\right]\right\}$

$\langle C\rangle$ : Average Concentration (mass/volume)

$\mathrm{G}^{*}$ : Amount of released gas (mass)

$\delta_{\mathrm{x}}, \delta_{\mathrm{y}}, \delta_{\mathrm{z}}$ : Dispersion Coefficients for $\mathrm{x}, \mathrm{y}, \mathrm{z}$ coordinate (length)

$\mathrm{U}$ : Wind velocity (length/time)

y : Cross Wind Direction (length)

$\mathrm{z}$ : Distance above the ground (length)

$\mathrm{H}$ : Leak point height

The coordinate values $\mathrm{x}, \mathrm{y}$, and $\mathrm{z}$ mean downwind distance, crosswind distance, and height above ground, respectively. The center of the instantaneously released 
gas cloud moves along both wind velocity and the elapsed time. So, the release point center could be calculated by the equation $\mathrm{x}=\mathrm{u} \cdot \mathrm{t}$. The equation (7) needs not both wind velocity value and the elapsed time because the equation (7) is used only for calculating the concentration of the puff center. However, the equation (7) could be modified into a function using wind velocity value and the elapsed time as input values. The modified equation is the following equation (8) [1].

Table 4. Dispersion Coefficient Equations for Gaussian Puff [1]

\begin{tabular}{|c|c|c|}
\hline Pasquill-Gifford Stability & $\boldsymbol{\delta}_{\mathbf{y}}(\mathbf{m})$ & $\boldsymbol{\delta z}(\mathbf{m})$ \\
\hline A & $0.18 \mathrm{x}^{0.92}$ & $0.60 \mathrm{x}^{0.75}$ \\
B & $0.14 \mathrm{x}^{0.92}$ & $0.53 \mathrm{x}^{0.73}$ \\
C & $0.10 \mathrm{x}^{0.92}$ & $0.34 \mathrm{x}^{0.71}$ \\
D & $0.06 \mathrm{x}^{0.92}$ & $0.15 \mathrm{x}^{0.70}$ \\
E & $0.04 \mathrm{x}^{0.92}$ & $0.10 \mathrm{x}^{0.65}$ \\
F & $0.02 \mathrm{x}^{0.89}$ & $0.05 \mathrm{x}^{0.61}$ \\
\hline
\end{tabular}

$$
\begin{aligned}
& \langle\mathrm{C}\rangle(\mathrm{x}, \mathrm{y}, \mathrm{z})=\frac{\mathrm{G}^{*}}{(2 \pi)^{3 / 2} \delta_{\mathrm{x}} \delta_{\mathrm{y}} \delta_{\mathrm{z}}} \exp \left[-\frac{1}{2}\left(\frac{\mathrm{y}}{\delta_{\mathrm{y}}}\right)^{2}\right] \times\left\{\exp \left[-\frac{1}{2}\left(\frac{\mathrm{z}-\mathrm{H}}{\delta_{\mathrm{z}}}\right)^{2}\right]+\exp \left[-\frac{1}{2}\left(\frac{\mathrm{z}+\mathrm{H}}{\delta_{\mathrm{z}}}\right)^{2}\right]\right\} \times \\
& \exp \left[-\frac{1}{2}\left(\frac{x-u t}{\sigma_{x}}\right)^{2}\right]
\end{aligned}
$$

The Gaussian equation result as a concentration is not useful to determine a consequence area. Actually, the consequence area is expected by a graph as called "Isopleths" which is a line correspond to a target concentration values [1].

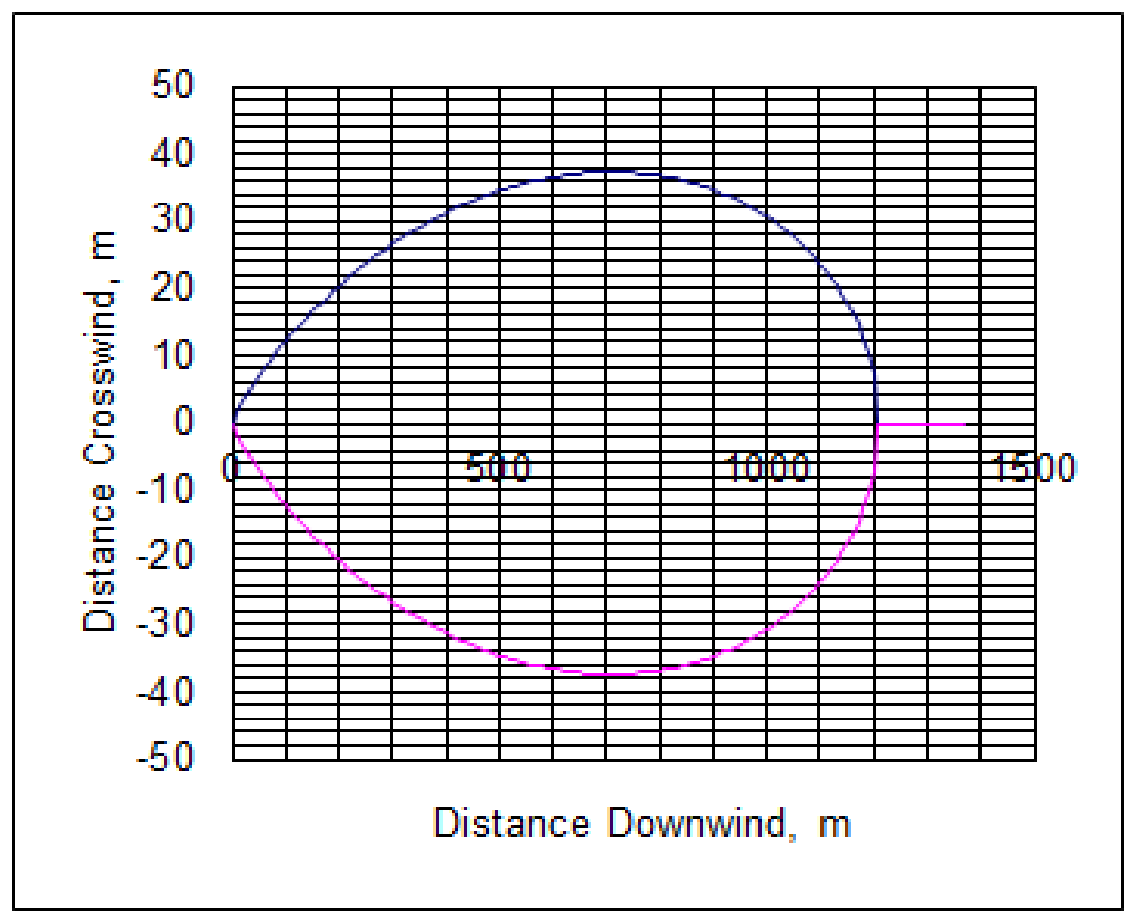

Figure 5. Example of Isopleths

The Figure 5 is isopleths of $10 \mathrm{ppm}$ concentration when a gas (molecular weight: $30 \mathrm{~mol}$ ) was continuous released at $50 \mathrm{~g} / \mathrm{s}$ leak rate, $0 \mathrm{~m}$ leak height, and $2 \mathrm{~m} / \mathrm{s}$ wind velocity. The circular line in the Figure 3 is corresponded to $10 \mathrm{ppm}$ concentration. 
Isopleths is the important factor for determining a consequence area and border line. CCPS introduces the following equation (9) to calculate y coordinate values for isopleths drawing on $\mathrm{x}-\mathrm{y}$ coordinates [1].

$$
y=\delta_{y} \sqrt{2 \ln \frac{\langle C\rangle(x, 0,0, t)}{\langle C\rangle(x, y, 0, t)}}
$$

Unfortunately, there are no any equations for fiding $\mathrm{z}$ coordinate values on $\mathrm{x}-\mathrm{z}$ coordinates. However, isopleths for $\mathrm{x}-\mathrm{z}$ coordinates could be generated by using numerical analysis methods. (※ Actually, it is possible to be expressed on a 3dimension coordinate for isopleths.) This study has used Matlab software for generating $\mathrm{x}-\mathrm{z}$ coordinate isopleths and applying numerical analysis methods.

\section{Programming Methods for Gaussian Equations}

\subsection{Numerical Analysis Methods for Gaussian Equations}

Drawing isopleths graph is the main goal of gas dispersion modeling. Amount of released gas (puff release) or Gas released rate (plume release) from discharge model could be easily calculated by using a calculator or by hand. And, isopleths on $x-y$ plane is easily generated by a simple equation (9). However, isopleths on $\mathrm{x}-\mathrm{z}$ plane needs more techniques than others. Isopleths drawing on $x-y$ plane requires many iterative calculations and numerical analysis methods.

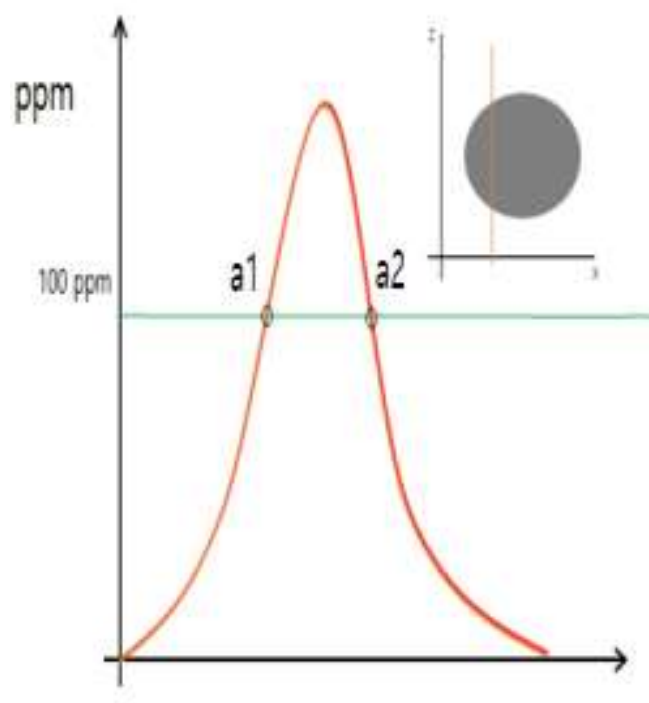

$z$

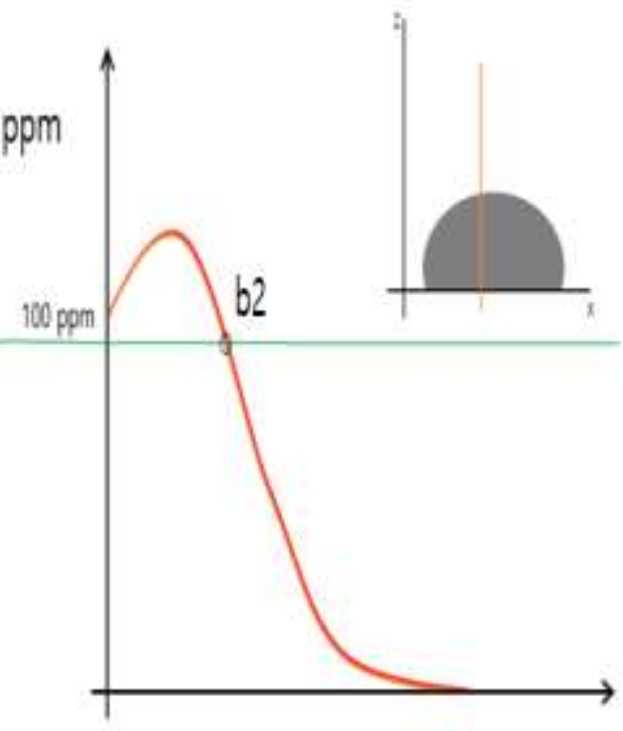

$z$

Figure 6. z Coordinate Value vs. ppm Graph for a x-z Isopleths

For drawing isopleths graph, engineers have to find points (a coordinate value) corresponding to a target concentration value. Figure 6 show coordinate value $\mathrm{z}$ vs. ppm graph on a fixed $\mathrm{x}$ and $\mathrm{y}$ value. the Figure 4 shows that there is one or two points corresponding to a target concentration value on fixed $\mathrm{x}$ and $\mathrm{y}$ value. And, these point values could be found by method as solving quadratic equation. On the other word, the isopleths drawing is to solve iteratively a quadratic equation for finding two $z$-values corresponding to a target concentration. 
Matlab software has its function for solving quadratic equation. However, instead of using the function, this study has try to program the solution algorithm with numerical analysis methods. Because, developing commercial software and reusing for other projects was considered. The following table lists numerical analysis methods for solving quadratic equation.

Newton method could save more resources if it is possible to get the differential equation of the Gaussian equation. However, newton method is not suitable for isopleths drawing. That is why Gaussian equation is to get differential equations too complex, and isopleths drawing requires iterative calculation on too many equations. Also, both newton method and secant method have a possibility that the iterative calculation is not converged. For this reason, newton method and secant method was not used in his study.

Table 5. Numerical Analysis Methods for Solving Quadratic Equation [3]

\begin{tabular}{|c|c|c|c|c|}
\hline Methods & $\begin{array}{c}\text { No. of initial } \\
\text { value }\end{array}$ & Rate of Convergence & $\begin{array}{c}\text { Speed of } \\
\text { Convergence }\end{array}$ & $\begin{array}{c}\text { Required } \\
\text { Functions }\end{array}$ \\
\hline Bisection-Method & 2 & Always convergent & Slow & $\mathrm{f}(\mathrm{x})$ \\
\hline Newton Method & 1 & Almost convergent & Fastest & $\mathrm{f}(\mathrm{x}), \mathrm{f}(\mathrm{x})$ \\
\hline $\begin{array}{c}\text { Secant } \\
\text { Method }\end{array}$ & 2 & Almost convergent & Fast & $\mathrm{f}(\mathrm{x})$ \\
\hline $\begin{array}{c}\text { False } \\
\text { Position }\end{array}$ & 2 & Always convergent & moderately fast & $\mathrm{f}(\mathrm{x})$ \\
\hline
\end{tabular}

This study has built two methods: using bisection method, and using alternately bisection method and false position method. When false position method used, the convergence speed is mostly faster at the beginning than when bisection method used. But, as the Figure 7, the convergence speed tends to be decreased near roots. At times, the values are not converged despite the system resource is used up.

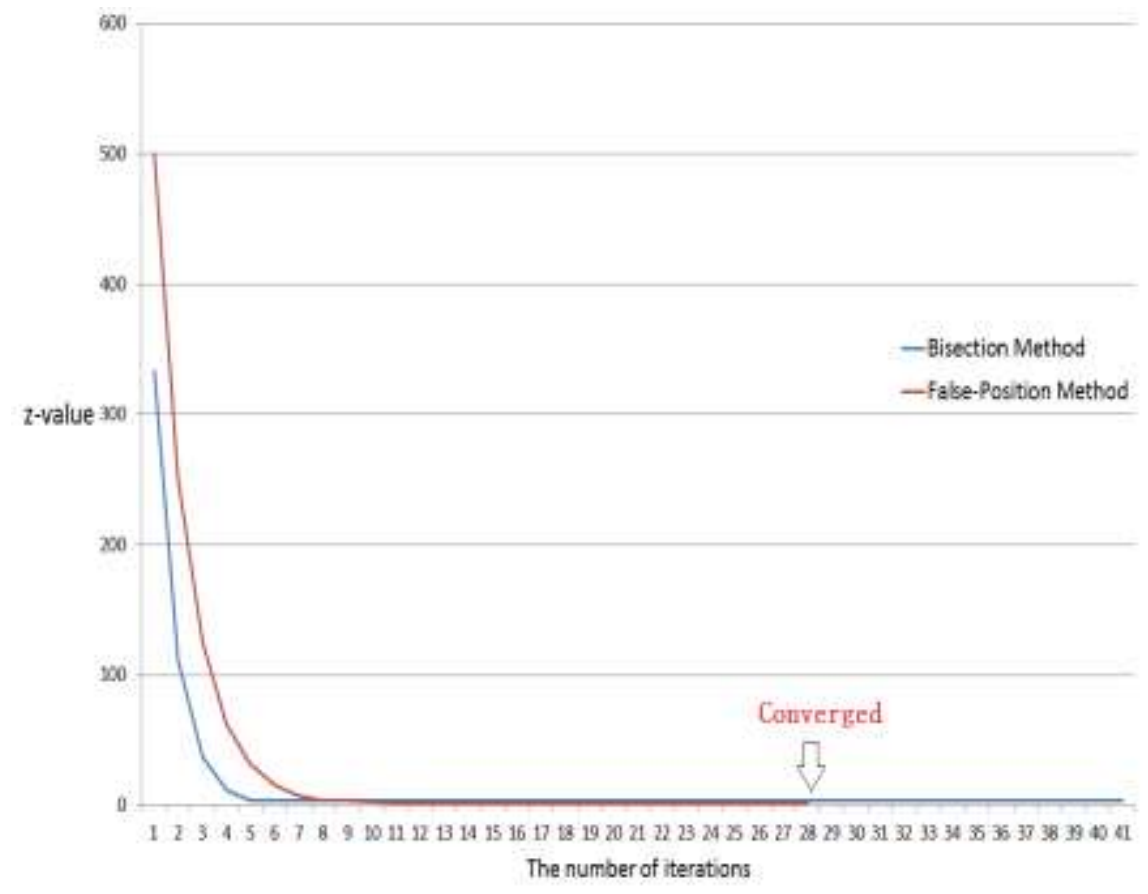

Figure 7. Comparison with the Convergence Speeds of Bisection Method and False-Position Method 


$$
\mathrm{x}_{\mathrm{n}}=\frac{\mathrm{a}_{\mathrm{n}}+\mathrm{b}_{\mathrm{n}}}{2}
$$

$$
x_{n}=a_{n}-\frac{f\left(a_{n}\right)}{m_{n}}
$$

False position equation is

$m_{n}=\frac{f\left(b_{n}\right)-f\left(a_{n}\right)}{b_{n}-a_{n}}(n=0,1,2, \ldots)$

$$
\text { Initial value: } a_{0}, b_{0} f\left(a_{0}\right) f\left(b_{0}\right) \leq 0
$$

The Table 6 shows average numbers of calculation required for finding $\mathrm{z}$-values according to an ethane gas continuous release scenario (Ref. Table 7). When bisection method used, average number of calculation was 23.89522. In fact, the convergence speed of bisection method is not bad to perform a drawing Isopleths in this study. However, this study has tried to find a new method to make up the weakness of false-position method in order to get ready for developed system extension and reused. Finally, this study used alternately bisection method and false position method and the try was successful. The average number of calculation was decreased more than $43 \%$.

\section{Table 6. The Average Numbers of Calculation Required for Finding z-Value}

\begin{tabular}{|l|l|}
\hline \multicolumn{1}{|c|}{ Numerical Methods } & \multicolumn{1}{c|}{ Average number of Calculation } \\
\hline Bisection Method & \multicolumn{2}{|c|}{23.89522} \\
\hline F-P Method & Not converged at times \\
\hline Alternating F-P and Bisection & \multicolumn{2}{|c|}{13.00228} \\
\hline
\end{tabular}

\subsection{Modular Programing}

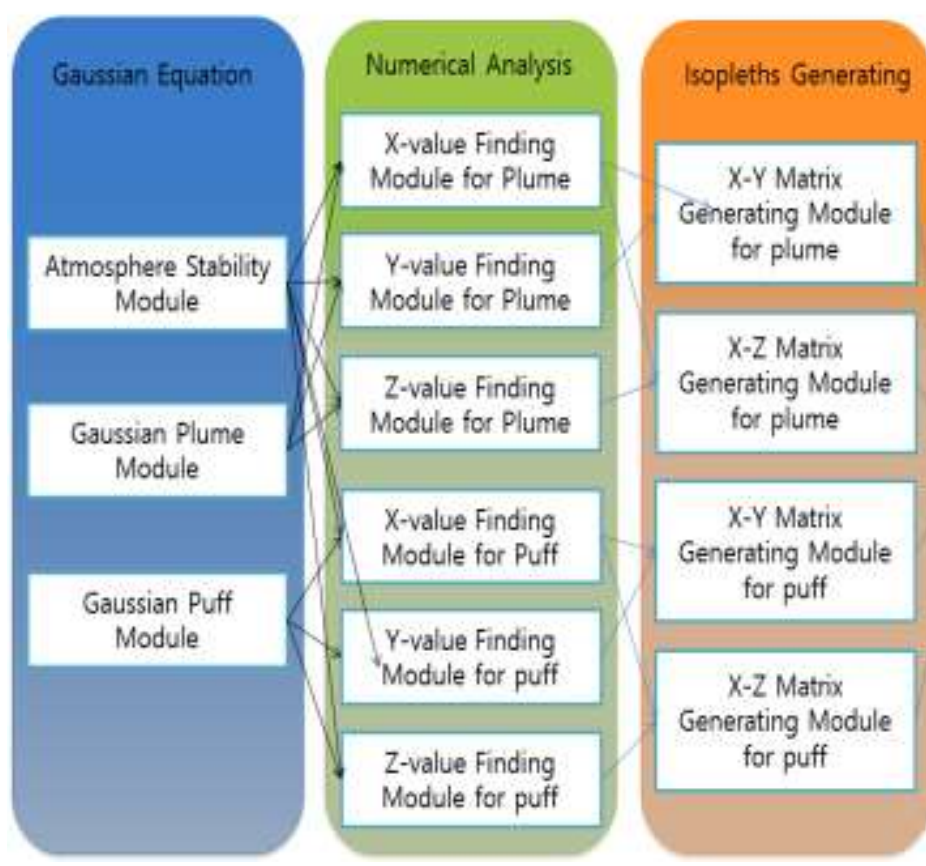

Plot Drawing Module

Figure 8. The Structure of Gas Disperse Module 
In this study, the gas dispersion model is a module of consequence analysis system in gas safety platform. And, the developed gas dispersion module is also a grouping of many sub-modules. The sub-modules are divided to 3 classes: Gaussian Equation class, Numerical Analysis class, and Isopleths Generating Class. Gaussian equation class is received input data as incident scenario information from users and solves Gaussian equation. Numerical analysis class tries to find $\mathrm{x}, \mathrm{y}$, and $\mathrm{z}$ coordinate values corresponding to target concentration by using Gaussian equation class. Isopleths Generating class gathers $\mathrm{x}, \mathrm{y}$, and $\mathrm{z}$ coordinate values from Numerical analysis. And the class produces a line from the $\mathrm{x}, \mathrm{y}$, and $\mathrm{z}$ points, and generates Isopleths matrix. Each submodule is intimately connected to others and they pass the data around each other. The Figure 8 shows the relationship between modules.

The main reason of modulation is for reuse and extension of developed gas dispersion module. This program needs to be merged with gas discharge module and harm potential module in order to build a complete consequence analysis system. And, Gaussian equation is suitable for neural gas, but not dense gas. [5] To expand the range, the system needs to adopt the dense gas dispersion models as BM model, SLAB model, or DEGADIS model. When a dense gas dispersion model is developed in future, the Gaussian model will be connected to the dense gas model. For these reasons, the modular programing is very useful.

\section{Gas Dispersion Graph}

\subsection{Gaussian Plume Graph}

As mentioned previously, Gaussian Plume model represents continuous released gas dispersion. The input values are leak rate, molar mass, atmospheric condition, wind velocity, temperature and pressure on leak point, and leak point height. In this paper, the following scenario (Table 7) is assumed for showing Gaussian plume graph examples.

Table 7. Ethane Gas Continuous Release Scenario

\begin{tabular}{|c|c|}
\hline Type & Ethane gas (C2H6) \\
\hline Release Rate & $0.01 \mathrm{~kg} / \mathrm{s}$ \\
\hline Release Source Height & $1.5 \mathrm{~m}$ \\
\hline Temperature & $298 \mathrm{~K}$ \\
\hline Pressure & $1 \mathrm{~atm}$ \\
\hline Pasquill Stability & $\mathrm{F}$ \\
\hline Wind velocity & $1.5 \mathrm{~m} / \mathrm{s}$ \\
\hline Terrain Classification & Urban area \\
\hline Target PPM & $3.0 \mathrm{PPM}$ \\
\hline
\end{tabular}


Table 8. Ethane Gas Properties [7]

\begin{tabular}{|l|l|}
\hline Chemical formula & $\mathrm{C}_{2} \mathrm{H}_{6}$ \\
\hline Molar mass & $30.07 \mathrm{~g} \cdot \mathrm{mol}^{-1}$ \\
\cline { 2 - 2 } Appearance & Colorless gas \\
\hline Odor & Odorless \\
\hline Density & $1.3562 \mathrm{~kg} / \mathrm{m}^{3}\left(\right.$ at $\left.0{ }^{\circ} \mathrm{C}, 101.3 \mathrm{kPa}\right)$ \\
\hline Melting point & $-182.8{ }^{\circ} \mathrm{C} ;-296.9^{\circ} \mathrm{F} ; 90.4 \mathrm{~K}$ \\
\hline Boiling point & $-88.5{ }^{\circ} \mathrm{C} ;-127.4{ }^{\circ} \mathrm{F} ; 184.6 \mathrm{~K}$ \\
\hline Solubility in water & $56.8 \mathrm{mg} \mathrm{L}-1\left(\right.$ at $\left.0{ }^{\circ} \mathrm{C}\right)$ \\
\hline Vapor pressure & $\left.3.8453 \mathrm{MPa}^{(a t} 21.1{ }^{\circ} \mathrm{C}\left(70.0{ }^{\circ} \mathrm{F}\right)\right)$ \\
\hline Henry's law constant $(\mathrm{kH})$ & $19 \mathrm{nmol} \mathrm{Pa}{ }^{-1} \mathrm{~kg}^{-1}$ \\
\hline Magnetic susceptibility $(\chi)$ & $-37.37 \cdot 10^{-6} \mathrm{~cm}^{3} / \mathrm{mol}^{-1}$ \\
\hline
\end{tabular}

Ethane gas is main molecular of natural gas. In Korea, chemical plants are usually in the city. So, urban area was chosen for terrain classification. Wind velocity and Pasquill stability are assigned 1.5 and $\mathrm{F}$ for a conservative approach. The target concentration is 3.0, which value is lower flammable limit of ethane gas. Figure 9 shows the gas dispersion isopleths graph of ethane gas release scenario (Table 7). And, the explosive atmosphere distance is $339 \mathrm{~m}$ on downwind direction from leak point.

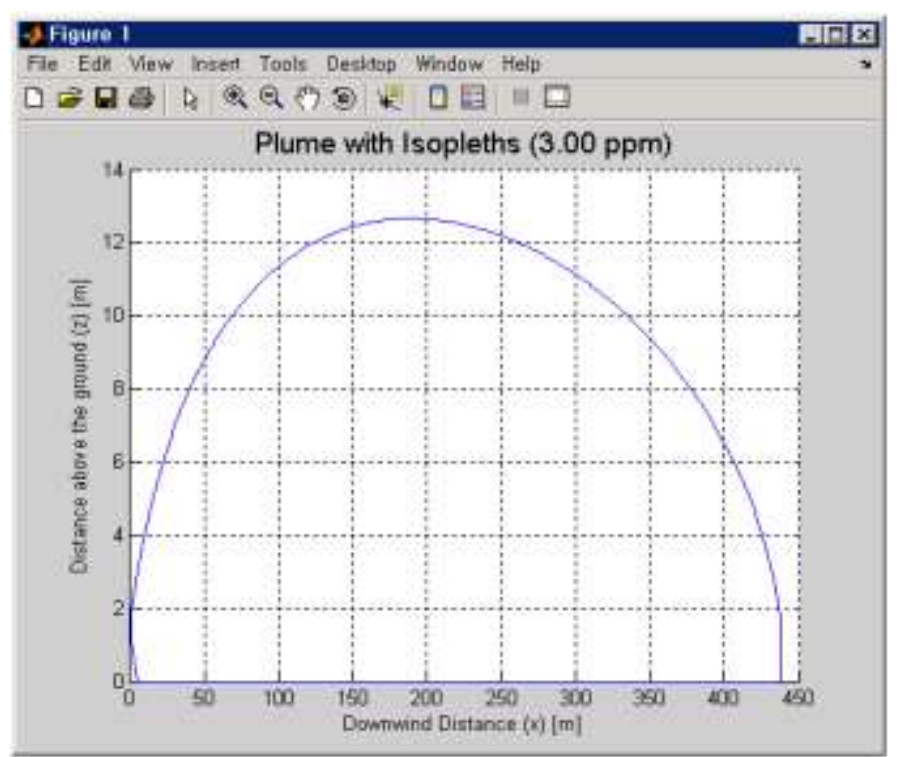

Figure 9. x-z Isopleths graph for Ethane Gas Releasing

The isopleths graph is able to be expressed in various ways with a change of variables such as y-value, release source height, wind speed, gas type, and Terrain Classification. 


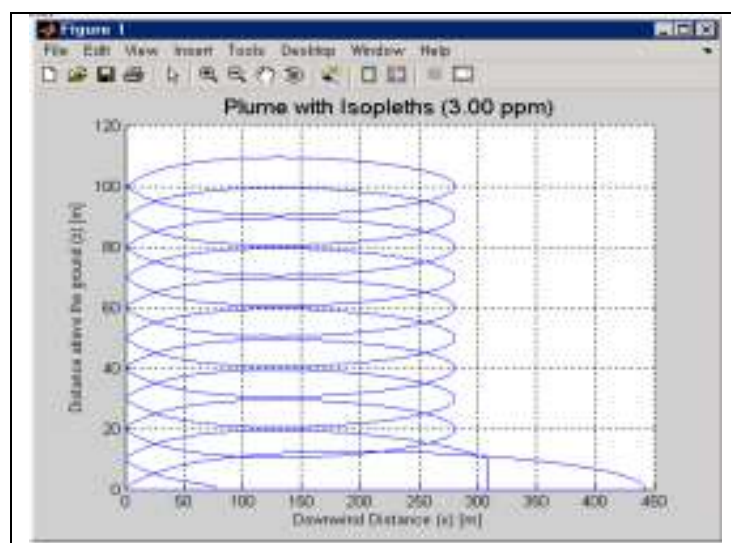

Isopleths with release height variations

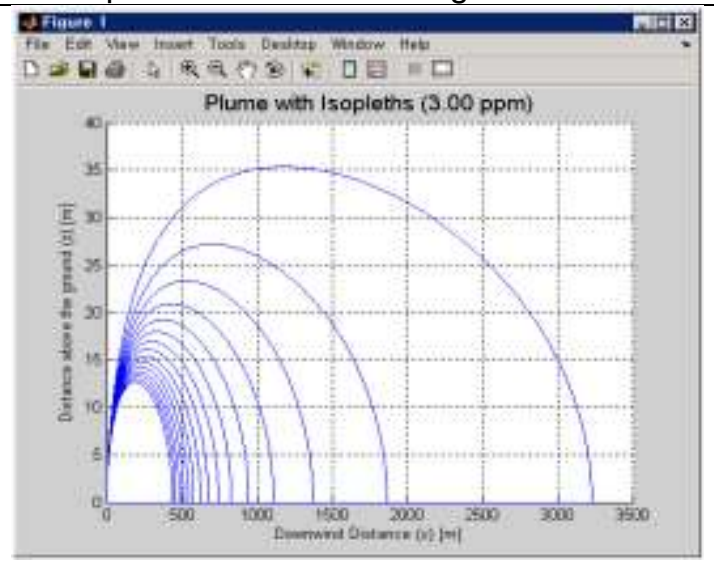

Isopleths with wind velocity variations

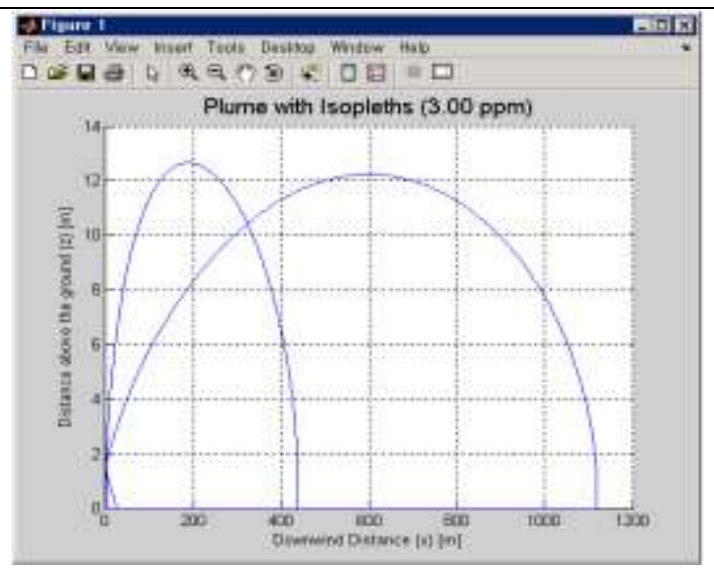

Isopleths on urban and rural area

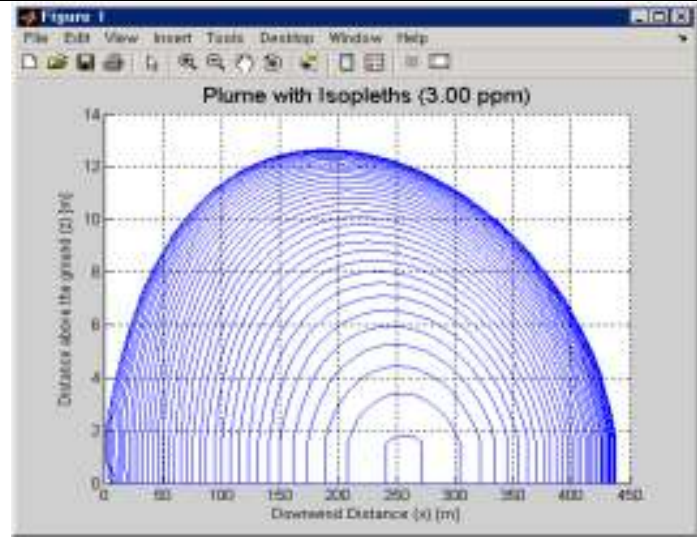

Isopleths with crosswind distance variations

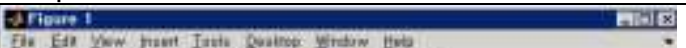

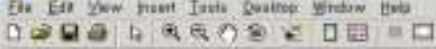

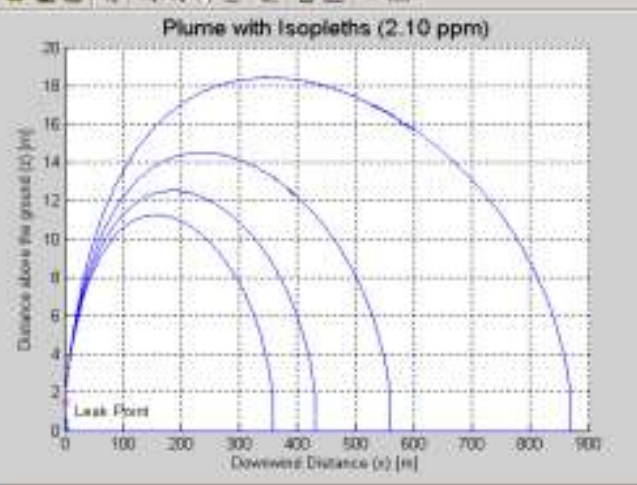

Isopleths with gas type variations(C1, C2, C3, C4)

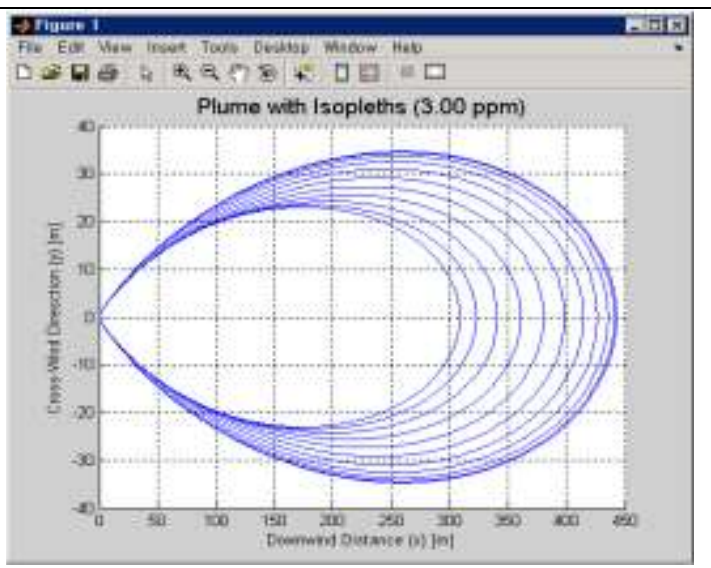

$x-y$ Isopleths with release height variations

Figure 10. Isopleths with Variables Changes

\subsection{Gaussian Puff Graph}

Gaussian puff equation uses the time as the input value. When the gas is instantaneously released, gas cloud is dispersed along wind velocity and corresponding to atmospheric stability. Gaussian puff graph could be expressed dynamically by time variable. For this reason, Gaussian puff isopleths may be required more system resources than Gaussian plume model. In the scenario (Table 9) for instantaneous release modeling, released ethane was assumed to be $0.1 \mathrm{~kg}$, and wind velocity and Pasquill stability were $1.5 \mathrm{~m} / \mathrm{s}$ and $\mathrm{A}$, respectively. Other scenario conditions ware equal in continuous release modeling. 
Table 9. Ethane Gas Instantaneous Release Scenario

\begin{tabular}{|c|c|}
\hline Type & Ethane gas (C2H6) \\
\hline Mass of Released Gas & $0.1 \mathrm{~kg} / \mathrm{s}$ \\
\hline Release Source Height & $1.5 \mathrm{~m}$ \\
\hline Temperature & $298 \mathrm{~K}$ \\
\hline Pressure & $1 \mathrm{~atm}$ \\
\hline Pasquill Stability & $\mathrm{A}$ \\
\hline Wind velocity & $0.1 \mathrm{~m} / \mathrm{s}$ \\
\hline Target PPM & $3.0 \mathrm{PPM}$ \\
\hline
\end{tabular}

As the Figure 11, 1100 seconds were spent until the gas disappeared from when the gas released. And the gas cloud was increased to the maximum size at about five-fifty hundred-seconds. When the increased time interval is set, the cloud shape and size could be easily recognized. On the contrary, when the decreased time interval is set, the trace of cloud moving is similar to the shape of plume cloud. From these graphs, golden time could be calculated for emergency response.

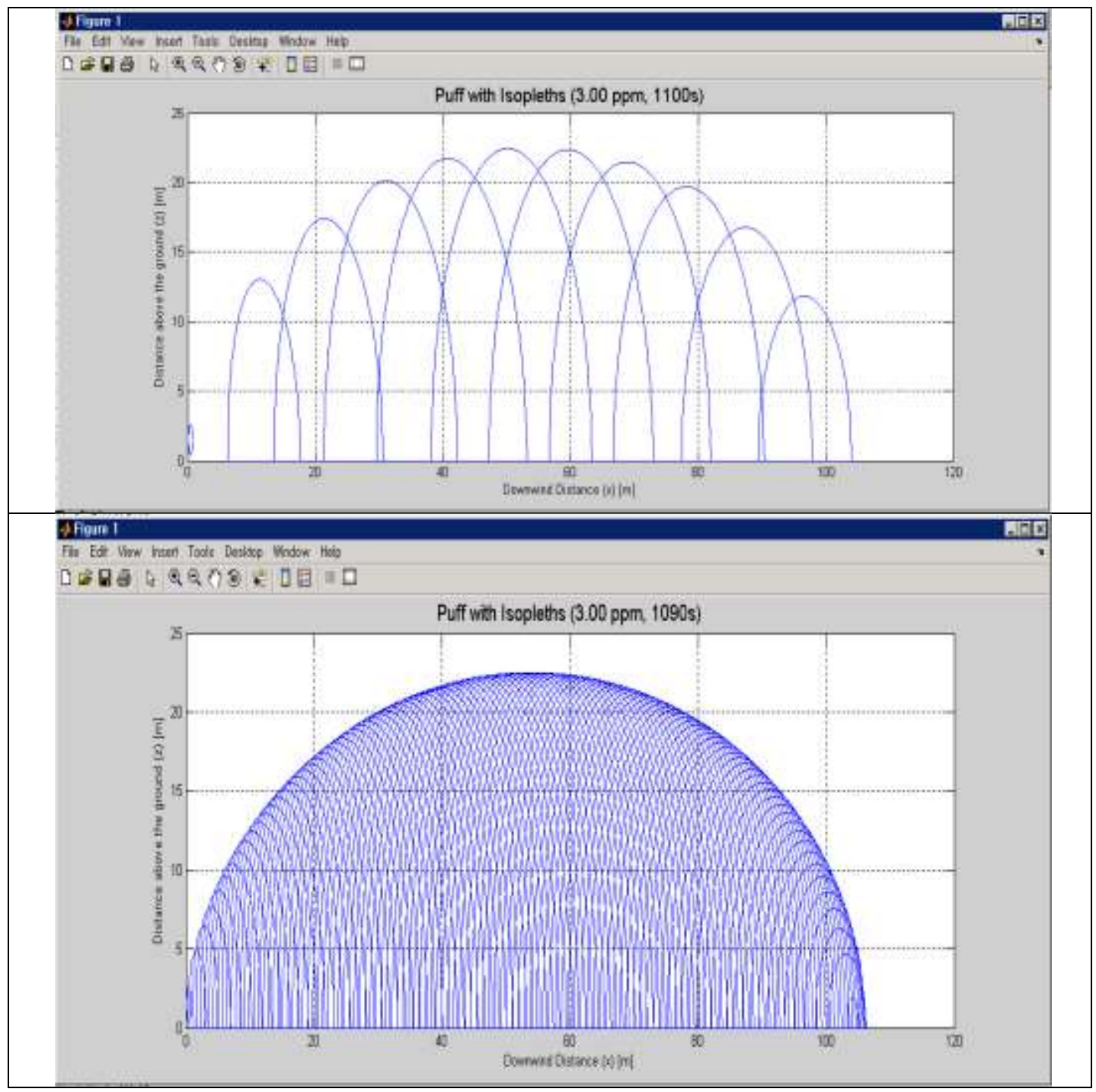

Figure 11. Instantaneous Release Isopleths with 100s Step and 10s Intervals 
The following graph (Figure 12) demonstrates the cloud moving in $\mathrm{x}-\mathrm{z}$ isopleths and $\mathrm{x}-$ $y$ isopleths at the enough height $(50 \mathrm{~m})$ for keeping released gas away from the ground.

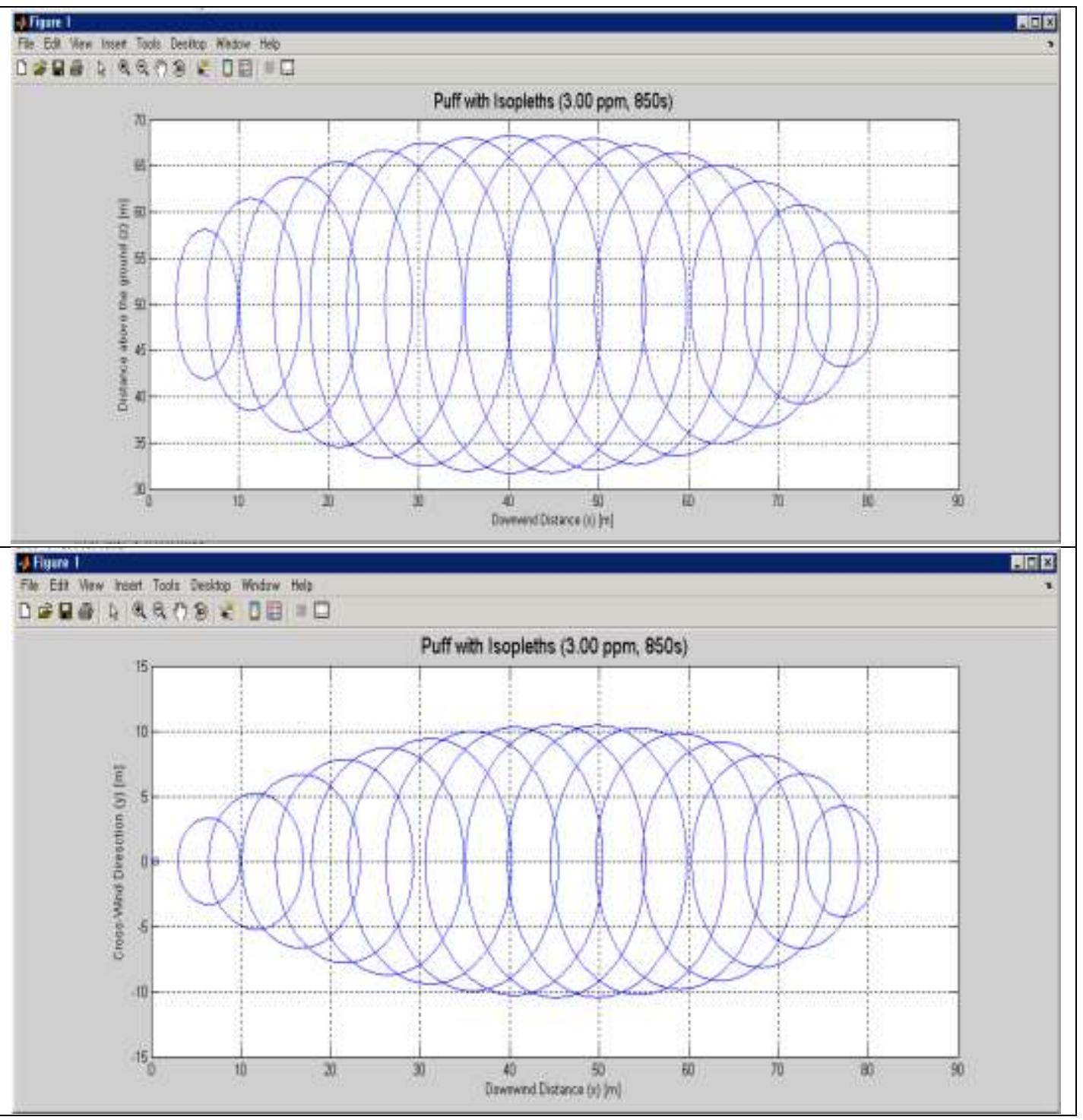

Figure 12. Comparison with $x-z$ Isopleths and $x-y$ Isopleths on $50 \mathrm{~m}$ Height (Height of Leak Point is also $50 \mathrm{~m}$ )

\section{Conclusion}

Gas dispersion modeling is a small part of the gas safety platform. However, gas dispersion modeling can exert a major influence on the outcome of consequence analysis, and consequence analysis is one of the major sections of the gas safety platform. The result of gas dispersion is very important in risk assessment, but that is not simple calculation.

The objective of this paper is to model for natural gas dispersion. The natural gas is composed with ethane and methane gases which is lighter than air. So, Gaussian equations are used because the equation is appropriative for lighter gas.

Proper numerical methods use could increase the performance and efficiency of the system. This paper show using alternately bisection method and false position method to decrease $43 \%$ of the number of iterative calculation. Also, modulating programing leads to increase the efficiency for reuse and extension of the developed module. 
The developed gas dispersion program may have lower accuracy in comparison with commercialized gas dispersion programs fully developed. However, this developed program is possible to be transformed freely by modularize structure. Also, this program will be updated, and the accuracy is also increasing by applied latest theory and comparison with commercialized software.

\section{Acknowledgments}

This work was supported by Energy Efficiency \& Resource Core Technology of Korea Institute of Energy and Planning (KETEP) granted financial resource from the Ministry of Trade, Industry \& Energy, Republic of Korea (No. 20172210100110)

\section{References}

[1] "Guidelines for Analysis of Chemical Releases", CCPS, (1999).

[2] "Methods for the calculation of physical effects", TNO Yellow Book, (2005).

[3] S. C. Chapra and R. P. Canale, "Numerical Methods for Engineers Six Edition", McGrawHill, (2009).

[4] J. S. Oh, "A study on Developing IGAS for Analyzing the Status of Gas Facility", International Journal of U- And E-Service, Science and Technology, ISSN 2015-4246, vol. 10, no. 7, (2017).

[5] D.M. Deaves, "Dense gas dispersion modeling", Journal of Loss Prevention in the Process Industries, vol. 5, Ilissue 4, (1992), pp. 219-227.

[6] J. Pullen, J. P. Boris, T.Young, G. Patnaik and J. Iselin, "A comparison of contaminant plume statistics from a Gaussian puff and ruban CFD model for two large cities", Atmospheric Environment, vol. 39, issue 6, (2005), pp. 1049-1068

[7] Wikipedia. Ethene. https://en.wikipedia.org/wiki/Ethane, (2017).

\section{Authors}

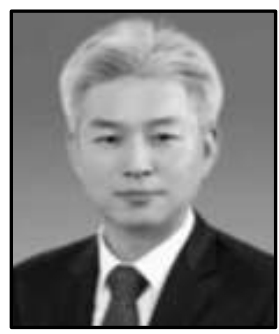

Jeong Seok Oh, he is a principal researcher at gas safety R\&D institute in Korea Gas Safety Corporation. He received M.Sc degree and Ph.D degree both in computer science department from Soongsil University in 1998 and 2006 respectively. He has published more than 40 articles in convergence field between gas safety and IT, His main research interests include industrial IoT, risk analysis based on combination safety technology and information technology.

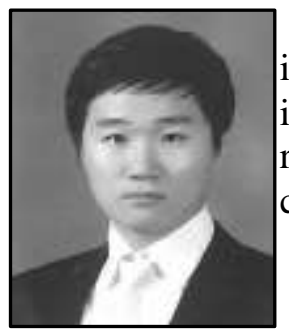

Ugwiyeon Lee, he is a research engineer at Gas Safety R\&D institute in Korea Gas Safety Corporation. He received master degree in chemical engineering from University of South Florida. He has researched on risk assessment methods, intelligence systems, and chemical process design based on gas safety technologies. 
International Journal of Control and Automation

Vol. 10, No. 12 (2017) 